\title{
VERIFICATION OF BRITTLE FRACTURE CRITERIA FOR BIMATERIAL STRUCTURES
}

\author{
Grzegorz MIECZKOWSKI*, Krzysztof MOLSKI \\ *Faculty of Mechanical Engineering, Białystok University of Technology, ul. Wiejska 45C, 15-351 Białystok, Poland \\ g.mieczkowski@pb.edu.pl, k.molski@pb.edu.pl
}

\begin{abstract}
The increasing application of composite materials in the construction of machines causes strong need for modelling and evaluating their strength. There are many well known hypotheses used for homogeneous materials subjected to monotone and cyclic loading conditions, which have been verified experimentally by various authors. These hypotheses should be verified also for composite materials. This paper provides experimental and theoretical results of such verifications for bimaterial structures with interfacial cracks. Three well known fracture hypotheses of: Griffith, McClintock and Novozhilov were chosen. The theoretical critical load values arising from each hypotheses were compared with the experimental data including uni and multi-axial loading conditions. All tests were carried out with using specially prepared specimens of steel and PMMA.
\end{abstract}

Key words: Fracture Criteria, Interfacial Crack, Delamination, Experimental Tests

\section{INTRODUCTION}

The development of composite structures and manufacturing technology allow the production of materials of specific strength and functional properties, which are more convenient for use in machine design. Selected in suitable proportions homogeneous components, when combined together, provide high stiffness and strength with a lower weight. In addition, reinforced with particles (molecular embedded in a matrix) composite materials exhibit better functional properties such as hardness, abrasion resistance and higher temperature work. Additionally, by using the reinforcement of the lower stiffness than the matrix, higher fracture toughness may be obtained (Wojciechowski et al. 1993). In many cases the properties of the composite material directly depend on the characteristics of the individual components.

Composite materials are characterized by macroscopic inhomogeneity of the structure where the local high stress gradients are produced by forced compatibility of displacements on the bond or caused by the local material discontinuities or sharp corners. This kind of stress raisers can generate singular stress fields of qualitative characteristics other than produced by the faults situated in a homogeneous material. Such mechanical fields can have multiple singularities described by real and complex exponents of particular terms when using asymptotic approach to the problem. These factors cause difficulties of strength estimations for such structures.

In many cases a theoretical method of homogenization of material properties may be useful (Woźniak 1987). Another approach to determining the strength of multiphase materials is based on the fracture parameters as generalized stress intensity factors related to the local stress field existing around the crack tips, can be found in the following papers: Salganik (1948), Williams (1959), Erdogan (1963), Rice and Sih (1965), Chen (1992) among others.

\section{MAIN OBJECTIVES AND ASSUMPTIONS OF THE WORK}

Most of the fracture mechanics hypotheses applied for estimating strength of homogeneous materials with stress raisers, such as sharp notches or cracks producing singular stress fields, have been verified experimentally by many authors, e.g. Murakami (1987), Seweryn and Łukaszewicz (2002). The correctness of their use in structural components made of composite materials with stress raisers producing qualitatively different stress fields, such as single or multiple "oscillatory" singularities, requires experimental verification.

The purpose of this work is to verify the three fracture strength hypotheses of Griffith, modified McClintock and Novozhilov, applied for predicting strength and fracture toughness of bi-material structures including interface cracks.

The present work is based on some general assumptions:

1. Both bonded materials can be considered as perfectly connected Hookean media.

2. Fracture process appears exclusively along the material interface. It means that fracture conditions are analyzed along the bond only and no such conditions are investigated separately for the homogeneous component.

3. There is no influence of the bonding material (glue) on the real stress distribution. Since the adhesive layer is very thin, instead of investigating real stress distribution we are focused on the predominant stress field produced by the "ideal" connection, which is a general base for calculating and comparing the critical parameters of the process. Similar assumption is usually made when analyzing fracture of a homogeneous material, where the influence of the small plastic zone is discarded, in spite of the fact that it may change the stress distribution at the vicinity of the crack tip.

4. Only cohesive damage mechanism is taken into account. 
These assumptions make it possible to use simplified mathematical apparatus for calculating basic critical parameters from the known formulas describing local stress fields along the bond.

\section{FRACTURE STRENGTH CRITERIA}

\subsection{Griffith energy criterion}

This criterion is based on the assumption that the brittle fracture occurs when the energy release rate $G$ reaches the critical value: $G=G_{c}$. For a structural element with an interfacial crack, $G$ parameter is expressed by formula (1) containing generalized stress intensity factors $K_{j}^{(\lambda r)}$ and material constants, as follows:

$G=\frac{1}{16 \cosh (\pi \delta)^{2}}\left(\frac{1+\kappa_{1}}{\mu_{1}}+\frac{1+\kappa_{2}}{\mu_{2}}\right)\left(K_{I}^{\left(\lambda_{r}\right)^{2}}+K_{I I}^{\left(\lambda_{r}\right)^{2}}\right)$

where:

$K_{I}^{\left(\lambda_{r}\right)}=\lim _{r \rightarrow 0} \sqrt{2 \pi} r^{1-\lambda_{r}}\left(\sigma_{\varphi}(r, 0) \cos (\Delta)+\tau_{r \varphi}(r, 0) \sin (\Delta)\right)$

$K_{I I}^{\left(\lambda_{r}\right)}=\lim _{r \rightarrow 0} \sqrt{2 \pi} r^{1-\lambda_{r}}\left(\tau_{r \varphi}(r, 0) \cos (\Delta)-\sigma_{\varphi}(r, 0) \sin (\Delta)\right)$

and $\mu_{\mathrm{i}}$ - shear modulus, $\mathrm{v}_{\mathrm{i}}$ - Poisson's ratio, $\kappa_{\mathrm{i}}=\frac{3-\mathrm{v}_{\mathrm{i}}}{1+\mathrm{v}_{\mathrm{i}}}$ for plane stress and $\kappa_{i}=3-v_{i}$ for plane strain, $\lambda_{r}$ - real part of the complex exponent, $\delta=\frac{1}{2 \pi} \ln \left(\frac{\kappa_{1} \mu_{2}+\mu_{1}}{\kappa_{2} \mu_{1}+\mu_{2}}\right)$ - imaginary part of the complex exponent, $\Delta=\delta \ln (r)$.

\subsection{McClintock criterion}

McClintock (1958) proposed strain fracture condition, assuming that the fracture occurs when the normal strain $\varepsilon_{\varphi}$ in a small distance $\rho_{c}$ ahead of the crack tip reaches the critical value:

$\varepsilon_{\varphi}\left(r=\rho_{c}\right)=\varepsilon_{c}$

In practice, the stress form of this criterion proposed by Ritchie (1973) is frequently used, where strains have been replaced by the corresponding stress components. Crack propagation occurs when the hoop stress $\sigma_{\varphi}$ at a finite distance $r=\rho_{\mathrm{c}}$ reaches the critical value $\sigma_{c}$ (Fig. 1). This condition can be written as:

$\max _{\varphi} \sigma_{\varphi}\left(r=\rho_{c}\right)=\sigma_{c}$

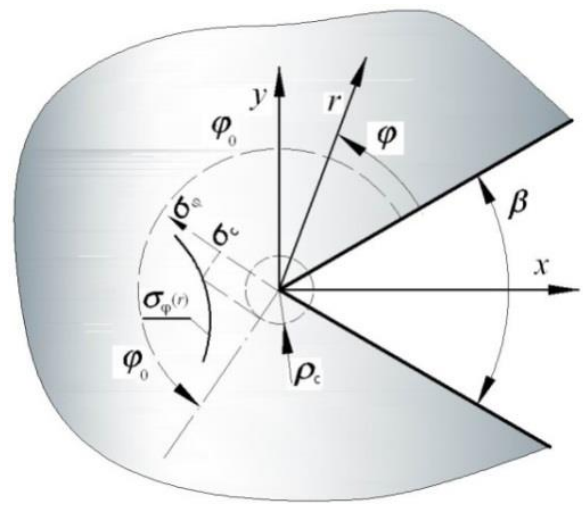

Fig. 1. Graphical interpretation of modyfied McClintock criterion
The characteristic parameter $\rho_{\mathrm{c}}$ is considered as a material constant and can be determined experimentally using formulas (5) and (6), where $K_{c}$ and $\sigma_{c}$ are known.

$$
\begin{gathered}
\frac{K_{\mathrm{Ic}}}{\sqrt{2 \pi \rho_{\mathrm{c}}}}=\sigma_{c} \\
\rho_{\mathrm{c}}=\frac{1}{2 \pi}\left(\frac{K_{\mathrm{Ic}}}{\sigma_{c}}\right)^{2}
\end{gathered}
$$

\subsection{Novozhilov non-local stress criterion}

Fracture criterion, proposed by Novozhilow (1969) and modified by Seweryn and Mróz (1998), assumes that the process of fracture occurs when the average stresses over a certain distance ahead of the notch root, represented by the stress function $\mathrm{R}_{\sigma}\left(\sigma_{n}, \tau_{n}\right)$, reaches the critical value causing material decohesion (Fig. 2). This condition can be written as follows:

$$
\max _{(\varphi)} \bar{R}_{\sigma}\left(\sigma_{n}, \tau_{n}\right)=\max _{(\varphi)}\left[\frac{1}{\mathrm{~d}_{0}} \int_{0}^{\mathrm{d}_{0}} \mathrm{R}_{\sigma}\left(\sigma_{\mathrm{n}}, \tau_{\mathrm{n}}\right) d r\right]=1
$$

where: $\overline{\mathrm{R}}_{\sigma}\left(\sigma_{\mathrm{n}}, \tau_{\mathrm{n}}\right)$ - non-local fracture function, $\mathrm{R}_{\sigma}\left(\sigma_{\mathrm{n}}, \tau_{\mathrm{n}}\right)-$ local fracture function, $\sigma_{n}, \tau_{n}$ - normal and shear stress on the physical plane, $r, \varphi$ - polar coordinates of reference system located at the top of the concentrator, $\mathrm{d}_{0}$ - damage zone size.

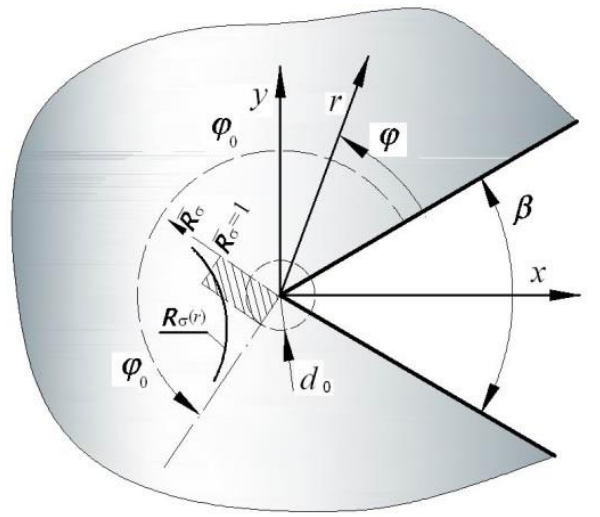

Fig. 2. Local fracture function $\mathrm{R}$, averaged in a plane ahead of the apex

The local stress function $\mathrm{R}_{\sigma}\left(\sigma_{\mathrm{n}}, \tau_{\mathrm{n}}\right)$ can be determined (depending on the type of the concentrator), for instance, in conditions of normal, equivalent or principal stresses. This criterion makes it possible to assess the critical load value as well as determine the direction of crack propagation, which corresponds to the maximum value of the nonlocal fracture function.

The value of the parameter $\mathrm{d}_{0}$ can be determined from the known fracture parameters as $K_{c}$ and $\sigma_{c}$, where the local fracture function is defined by a hoop stress $\mathrm{R}_{\sigma}\left(\sigma_{\mathrm{n}}, \tau_{\mathrm{n}}\right)=\sigma_{\varphi}$.

$\frac{1}{d_{0}} \int_{0}^{d_{0}} \frac{K_{\mathrm{Ic}}}{\sqrt{2 \pi \mathrm{r}}} d r=\sigma_{c}$

Thus, formula (9) provides solution for $\mathrm{d}_{0}$ :

$\mathrm{d}_{0}=\frac{1}{2 \pi}\left(\frac{2 K_{\mathrm{Ic}}}{\sigma_{c}}\right)^{2}$ 


\section{MATERIAL AND METHOD}

\subsection{Test specimens}

The specimens used in the experimental studies are presented in Fig. 3. All samples have been prepared by connecting two different parts of steel and PMMA plates but the same thickness. Both parts were glued symmetrically using Loctite 401 and leaving three cracks - a central and two lateral interfacial cracks. Internal surfaces of the connections have been specially shaped to form a symmetrical arched crack in the middle of specimens, providing good fitting of the components and causing fracture along the interface.

All specimen dimensions are presented in Tab. 1.

a)

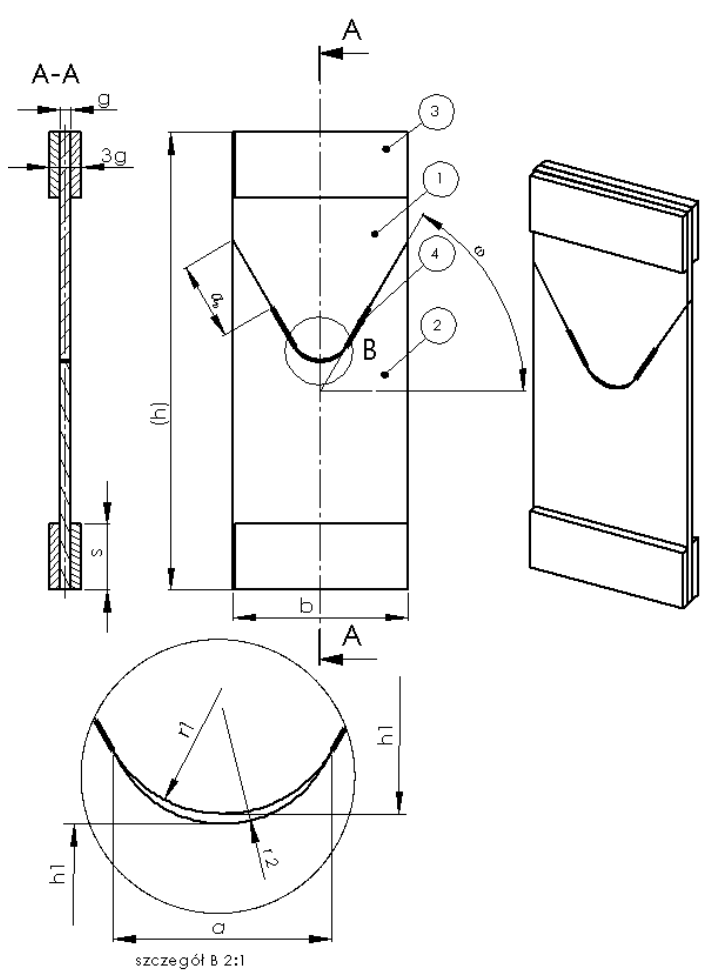

b)

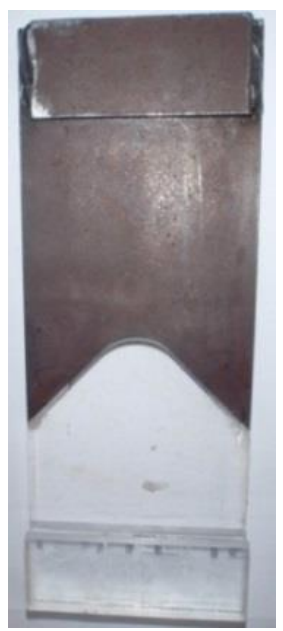

Fig. 3. Bimaterial specimen with interfacial cracks: a) geometrical characteristics: 1 - S235JR steel, 2 - PMMA, 3 - straps, 4 - connection zone; b) SP45PL specimen $\left(\omega=-45^{\circ}\right)$
Tab. 1. Basic dimensions of the specimens with interfacial cracks

\begin{tabular}{|c|c|c|c|c|c|}
\hline No. & Symbol & $\begin{array}{c}\omega \\
{\left[{ }^{\circ}\right]}\end{array}$ & $\begin{array}{c}\mathrm{r} 1 \\
{[\mathrm{~mm}]}\end{array}$ & $\begin{array}{c}\mathrm{r} 2 \\
{[\mathrm{~mm}]}\end{array}$ & $\mathrm{h}[\mathrm{mm}]$ \\
\hline 1 & SP60PL & -60 & 16 & 17.4 & 251.4 \\
\hline 2 & SP45PL & -45 & 18 & 21.3 & 251.4 \\
\hline 3 & SP30PL & -30 & 22 & 30 & 251.2 \\
\hline 4 & SP0 & 0 & 120 & 120 & 196 \\
\hline 5 & SP30S & 30 & 30 & 22 & 251.2 \\
\hline 6 & SP45S & 45 & 21.3 & 18 & 251.4 \\
\hline 7 & SP60S & 60 & 17.4 & 16 & 251.4 \\
\hline$a[\mathrm{~mm}]=30, \mathrm{~b}[\mathrm{~mm}]=96, \mathrm{~g}[\mathrm{~mm}]=6, \mathrm{~s}[\mathrm{~mm}]=36, \mathrm{~h} 1[\mathrm{~mm}]=125$ \\
\hline
\end{tabular}

For all specimens the gluing process was performed in similar conditions (compression, time etc.) by using a specially designed device. We also monitored temperature and humidity.

\subsection{Testing procedure and damage mechanisms}

All tests have been carried out on the hydraulic machine INSTRON 8502 equipped with additional proving ring positioned between the specimen and the upper holder of the machine. This dynamometer allowed to increase the accuracy of the load applied. In order to provide alignment of load the specimens have been mounted in a specially designed holder, shown in Fig. 4.

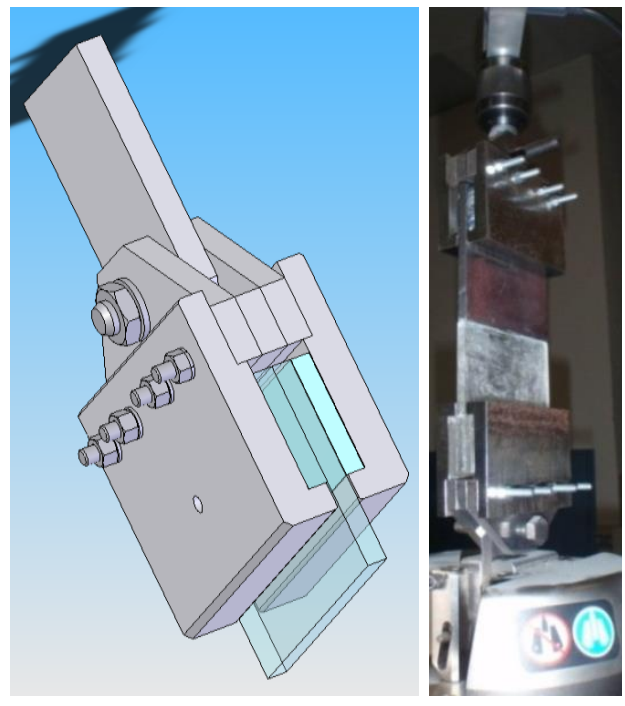

Fig. 4. Specially designed specimen holders used during testing

For all types of specimens fracture occurred along the interface. Next, it was necessary to analyse fracture surfaces in order to distinguish between a cohesive fracture and the adhesive damage. This was determined in two different ways. Firstly, all fractured specimens were valuated visually. In case of cohesive damage, a small rough layer was found on both surfaces - steel and PMMA. When adhesive failure occurred, the steel surface was clean and free from any particles.

Secondly, both damage mechanisms - adhesion and cohesion - were analysed by considering breaking force values. Critical forces for adhesive damage were significantly lower than these corresponding to cohesive fracture. So all results obtained for adhesive damage were omitted. The number of tested specimens 
of the same shape depended on the discrepancy of the critical force and the angle $\omega$ (Fig. 3), and varied from 7 to 13.

\section{EXPERIMENTAL AND THEORETICAL RESULTS}

Tab. 2. Critical values of stress $\sigma_{c}$ and the stress intensity factor $K_{c}$

\begin{tabular}{|l|c|}
\cline { 2 - 2 } \multicolumn{1}{c|}{} & Loctite 401 \\
\hline$\sigma_{\mathrm{c}}[\mathrm{MPa}]$ & 17 \\
\hline$K_{\mathrm{c}}\left[\mathrm{MPa} \mathrm{m}{ }^{1 / 2}\right]$ & 0.679 \\
\hline
\end{tabular}

Tab. 3. Parameters defining the length of the damage zones

\begin{tabular}{|c|c|c|}
\cline { 2 - 3 } \multicolumn{1}{c|}{} & $\begin{array}{c}\text { McClintock } \\
\rho_{c}[\mathrm{~mm}]\end{array}$ & $\begin{array}{c}\text { Novozhilov } \\
d_{0}[\mathrm{~mm}]\end{array}$ \\
\hline Loctite 401 & 0.254 & 0.404 \\
\hline
\end{tabular}

Tab. 4. Critical forces $\mathrm{Fc}[\mathrm{N}]$ obtained from experiments and calculated using various hypotheses

\begin{tabular}{|c|c|c|c|c|}
\hline \multirow{3}{*}{$\begin{array}{c}\text { Specimen } \\
\text { type }\end{array}$} & \multirow{3}{*}{$\begin{array}{c}\text { Critical forces Fc [N] } \\
\text { determined } \\
\text { experimentally }\end{array}$} & \multicolumn{3}{|c|}{ Criteria } \\
\hline & & Novozhilov & McClintock & Griffith \\
\hline & & $\mathrm{Fc}[\mathrm{N}]$ & $\mathrm{Fc}[\mathrm{N}]$ & $\mathrm{Fc}[\mathrm{N}]$ \\
\hline \multirow{3}{*}{ SP60PL } & 1423 & $1244 \mathrm{H}$ & $1584 \mathrm{H}$ & \multirow{3}{*}{1399} \\
\hline & 1441 & $976 \mathrm{R}$ & $1403 R$ & \\
\hline & $\sum F_{c_{i}} / i=1432$ & $972 \mathrm{P}$ & $1339 P$ & \\
\hline \multirow{3}{*}{ SP45PL } & 1056 & \multirow{3}{*}{$\begin{array}{r}1040 \mathrm{H} \\
1058 \mathrm{R} \\
969 \mathrm{P}\end{array}$} & \multirow{3}{*}{$\begin{array}{l}1362 \mathrm{H} \\
1493 \mathrm{R} \\
1336 \mathrm{P}\end{array}$} & \multirow{3}{*}{1097} \\
\hline & 1063 & & & \\
\hline & $\Sigma \mathrm{Fc}_{\mathrm{i}} / \mathrm{i}=1059$ & & & \\
\hline \multirow{5}{*}{ SP30PL } & 1283 & \multirow{5}{*}{$\begin{array}{l}1169 \mathrm{H} \\
1266 \mathrm{R} \\
1137 \mathrm{P}\end{array}$} & \multirow{5}{*}{$\begin{array}{l}1577 \mathrm{H} \\
1663 \mathrm{R} \\
1504 \mathrm{P}\end{array}$} & \multirow{5}{*}{1283} \\
\hline & 1199 & & & \\
\hline & 1172 & & & \\
\hline & 1254 & & & \\
\hline & $\sum \mathrm{Fc}_{\mathrm{c}} \mathrm{l} / \mathrm{i}=1227$ & & & \\
\hline \multirow{5}{*}{ SPO } & 1664 & \multirow{5}{*}{$\begin{array}{l}1570 \mathrm{H} \\
1419 \mathrm{R} \\
1349 \mathrm{P}\end{array}$} & \multirow{5}{*}{$\begin{array}{l}2176 \mathrm{H} \\
1791 \mathrm{R} \\
1751 \mathrm{P}\end{array}$} & \multirow{5}{*}{1621} \\
\hline & 1696 & & & \\
\hline & 1708 & & & \\
\hline & 1728 & & & \\
\hline & $\Sigma \mathrm{Fc}_{\mathrm{c}} / \mathrm{l}=1699$ & & & \\
\hline \multirow{4}{*}{ SP30S } & 703 & \multirow{4}{*}{$\begin{array}{l}737 \mathrm{H} \\
785 \mathrm{R} \\
709 \mathrm{P}\end{array}$} & \multirow{4}{*}{$\begin{array}{r}973 \mathrm{H} \\
1091 \mathrm{R} \\
970 \mathrm{P}\end{array}$} & \multirow{4}{*}{714} \\
\hline & 660 & & & \\
\hline & 685 & & & \\
\hline & $\sum \mathrm{Fc}_{\mathrm{i}} / \mathrm{i}=683$ & & & \\
\hline \multirow{5}{*}{ SP45S } & 723 & \multirow{5}{*}{$\begin{array}{r}882 \mathrm{H} \\
717 \mathrm{R} \\
705 \mathrm{P}\end{array}$} & \multirow{5}{*}{$\begin{array}{r}1127 \mathrm{H} \\
1030 \mathrm{R} \\
973 \mathrm{P}\end{array}$} & \multirow{5}{*}{692} \\
\hline & 678 & & & \\
\hline & 742 & & & \\
\hline & 607 & & & \\
\hline & $\Sigma \mathrm{Fc}_{\mathrm{i}} / \mathrm{i}=688$ & & & \\
\hline \multirow{4}{*}{ SP60S } & 927 & \multirow{4}{*}{$\begin{array}{r}1079 \mathrm{H} \\
562 \mathrm{R} \\
638 \mathrm{P}\end{array}$} & \multirow{4}{*}{$\begin{array}{r}1319 \mathrm{H} \\
797 \mathrm{R} \\
863 \mathrm{P}\end{array}$} & \multirow{4}{*}{891} \\
\hline & 908 & & & \\
\hline & 960 & & & \\
\hline & $\sum \mathrm{F}_{\mathrm{i}} / i=932$ & & & \\
\hline \multicolumn{4}{|c|}{$\begin{array}{l}\text { Damage functions applied to fracture criteria: } \mathrm{P} \text { - principal } \\
\text { stress, } \\
\mathrm{H} \text { - hoop stress normal to the fracture direction, } \mathrm{R} \text { - reduced, }\end{array}$} & \\
\hline
\end{tabular}

Huber-von Mises-Hencky equivalent stress

The critical forces - obtained experimentally and calculated theoretically, using various hypotheses - are shown in Tab. 4. In order to calculate critical stress intensity factors, energy release rates $G_{c}$ and critical forces obtained from investigated fracture strength hypotheses, the numerical FEM solutions have been performed and definitions of the stress intensity factors given by the formula (2) were applied.

In order to calculate critical forces using various hypotheses some material parameters had to be determined. Due to the fact that crack propagation proceeded along the bond these parameters have been determined for glue used in experiments (Loctite 401). The critical values of the stress intensity factor $K_{c}$ and the critical stresses $\sigma_{c}$ for the bond have been obtained experimentally from fracturing two halves of the same material with and without a central crack. These critical parameters as well as damage zone sizes are given in Tab. 2 and Tab. 3 .

Application of the hypotheses described in chapter 3 (except the Griffith criterion) requires analytical description of the stress field occurring around the tip of interfacial crack. The proper formulas are known from the literature e.g. by Erdogan (1963) and Molski and Mieczkowski (2004).

When testing Novozhilov and McClintock criteria, independent verification was performed using the maximum principal stress, the normal stress to the direction of fracture (hoop stress) and reduced equivalent stress by $\mathrm{H}-\mathrm{M}-\mathrm{H}$ hypothesis, as a function of damage. In the asymptotic solution there was taken into account only the first singular term.

Critical forces obtained from the experimental tests and hypotheses tested are shown in Tab. 4 and illustrated graphically in Fig.5 and 6.

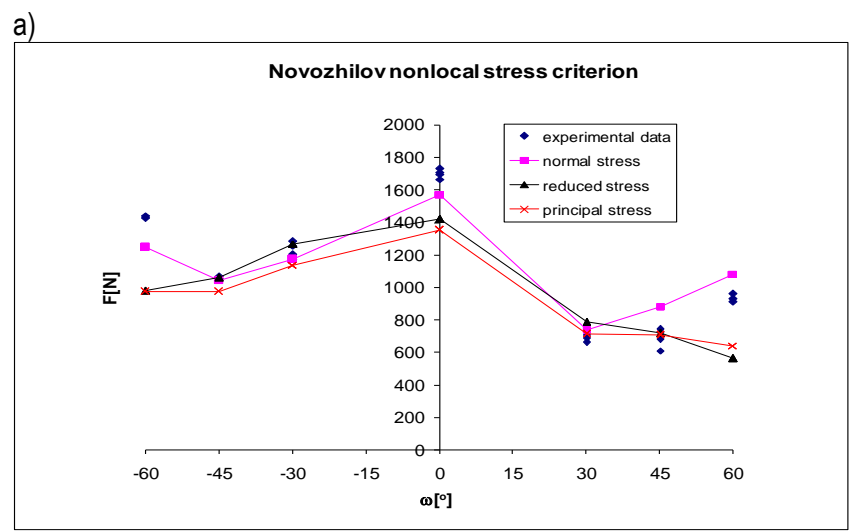

b)

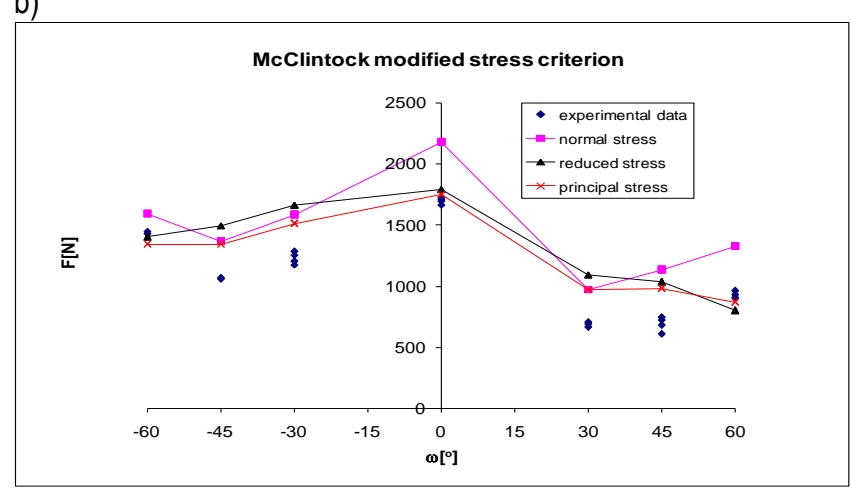

Fig. 5. Comparison of critical load values obtained from tests (a-Novozhilov, b-McClintock) with experimental data for different damage functions vs interfacial crack angle 


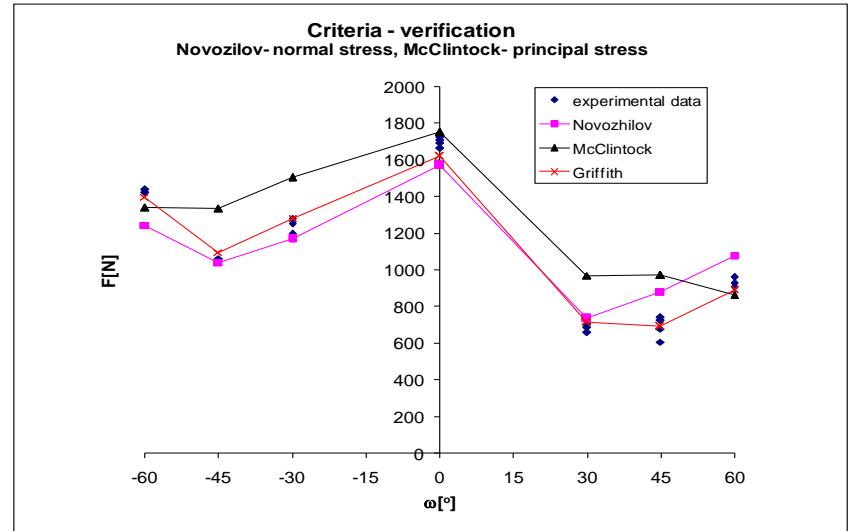

Fig. 6. Comparison of critical load vs. $w$ angel obtained from test and calculated using various criteria

\section{CONCLUSIONS}

In the comparison of critical forces obtained from the experimental tests with the evaluated theoretical data leads to the following conclusions:

- the most accurate results were obtained using the Griffith criterion taking into account proportions between the normal and tangential stresses at the interface;

- for the Novozhilov criterion, most accurate results were obtained for the normal hoop stresses considered as a damage function;

- for the McClintock criterion - the maximum principal stresses considered as a damage function gave the most accurate values of the critical force.

\section{REFERENCES}

1. Chen D.H. (1992), Analysis for corner singularity in composite materials based on the body force method. Computational Methods in Fracture Mechanics, Fatigue and Fracture Mechanics, Comp. Mech. Publ., Southampton, 397-421.

2. Erdogan F. (1963), Stress Distribution in a Non-homogeneous Elastic Plane with Cracks, Trans. ASME, Ser. E, J. Applied Mechanics, 30, 232-236.

3. Griffith A.A. (1920), The phenomena of rupture and flow In solids, Philosophical Transactions, series A, Vol. 221, 163-198.
4. McClintock F. A. (1958), Ductile fracture instability in shear, Trans. ASME, J. Appl. Mech., Vol. 25, 582-588.

5. Mieczkowski G., Molski K. (2005), Stress field singularities for reinforcing fibre with single lateral crack, Solid Mechanics and lts Applications, Springer Verlag, 135, 185-192.

6. Mieczkowski G., Molski K. (2009), Energy Release Rate G as a Fracture Parameter of a Bi-Material Structure Steel-Pmma with Interfacial Crack, Acta Mechanica et Automatica, Vol.3, nr 2, 52-54 (in polish).

7. Mieczkowski G., Molski K., Seweryn A. (2007), Finite element modelling of stresses and displacements near the tips of pointed inclusions, Materials Science, Vol. 42, 183-194.

8. Molski K, Mieczkowski G. (2008), Multiple stress field singularities for cracks described by real and complex exponents, Machine Dynamics Problems, Vol.32, nr 3, 72-79.

9. Molski K.L. Mieczkowski G. (2004), Local displacement effects in the vicinity of interfacial crack tip, Fracture Mechanics of Materials and Structural Integrity, Academician of NASU V.V. Panasyuk, 325331

10. Murakami Y. ed. (1987), Stress Intensity Factors Handbook, Pergamon Press.

11. Novozhilov V. V. (1969), On necessary and sufficient criterion of brittle fracture, Prikl. Mat. Mech., Vol. 33, 212-222 (in Russian).

12. Rice J.R., Sih G.C. (1965), Plane Problems of Cracks in Dissimilar Media. Trans. ASME, Ser. E, J. Applied Mech., Vol. 32, 418-423.

13. Ritchie R. O. (1973), Knott J. F., Rice J. R., On the relation between critical tensile stress and fracture toughness in mild steel, J. Mech. Phys. Solids, Vol. 21, 395-410.

14. Salganik R.L. (1948), The Brittle Fracture of Cemented Bodies, Prokl. Mat. Mech., 27.

15. Seweryn A, kukaszewicz A. (2002), Verification of brittle fracture criteria for elements with $\mathrm{V}$-shaped notches, Engineering Fracture Mechanics, 691487-1510.

16. Seweryn A., Mróz Z. (1998), On the criterion of damage evolution for variable multiaxial stress states, International Journal Solid Structures, Vol. 35, 1589-1616.

17. Wen S., Chung D.D.L. (1999), Seebeck effect in carbon fiber reinforced cement, Cement and Concrete Research, 29, 1989.

18. Williams M.L. (1959), The Stresses around a Fault or Crack in Dissimilar Media, Buli Seismol. Soc. Amer., 49, 199-204

19. Willis J.R. (1971), Fracture Mechanics of Interfacial Cracks, J. Mech. And Phys. Solids, Vol. 19, 353-368.

20. Wojciechowski S., Kapuściński J., Puciłowski K. (1993), Composites: fundamentals of design and manufacturing, OWPW (in polish)

21. Woźniak Cz. (1987), Nonstandard analysis and microlocal effects in the multilayered bodies, Bull. Pol. Ac.: Tech., 34, 385-392. 